\section{Prolegómenos}

Derecho y Valores
Prolegómenos. Derechos y Valores

ISSN: 0121-182X

derechos.valores@umng.edu.co

Universidad Militar Nueva Granada

Colombia

Henao Orozco, Rubén Darío

Tutela contra sentencias de las altas cortes o choque de vanidades

Prolegómenos. Derechos y Valores, vol. IX, núm. 17, enero-junio, 2006, pp. 129-137

Universidad Militar Nueva Granada

Bogotá, Colombia

Disponible en: http://www.redalyc.org/articulo.oa?id=87601709

Cómo citar el artículo

- Número completo

- Más información del artículo

Página de la revista en redalyc.org

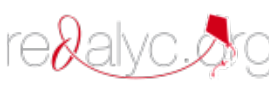

Sistema de Información Científica

Red de Revistas Científicas de América Latina, el Caribe, España y Portugal

Proyecto académico sin fines de lucro, desarrollado bajo la iniciativa de acceso abierto 


\title{
TUTELA CONTRA SENTENCIAS DE LAS \\ ALTAS CORTES O CHOQUE DE VANIDADES *
}

\section{TRUSTEESHIP AGAINST SENTENCES OF THE HIGH COURTS OR SHOCK OF VANITIES}

\author{
Rubén Darío Henao Orozco \\ Consejo Superior de la Judicatura. \\ Fecha de recepción: Febrero 27 de 2006. \\ Fecha de aceptación: Marzo 30 de 2006.
}

\section{Resumen}

"La acción de tutela - o el llamado recurso de amparo o recurso de constitucionalidad- contra sentencias constituye uno de los ejes centrales de todo el sistema de garantía de los derechos fundamentales."

Se limita el tema a la tutela contra sentencias de las Altas Cortes, porque ya es claro y no suscita ninguna controversia, el amparo contra sentencias emanadas por los Tribunales de Distrito Judicial, Contencioso Administrativos y los demás Jueces de la República. En cambio, cuando se produce una acción de tutela Que protege derechos fundamentales vulnerados por una sentencia de una Alta Corte, la Corte accionada se rasga las vestiduras y protagoniza el respectivo espectáculo ante los medios de comunicación, y el argumento Que inequívocamente trae a cuento en este show publicitario, es que dicha Corporación es un órgano límite y sus competencias emanan de la Constitución Política, además de ser exclusivasy excluyentes.

\footnotetext{
*Una versión preliminar de este artículo fue presentada como Conferencia dentro del IV Congreso Antioqueño en Derecho Procesal, y apareció publicado en las memorias de dicho Foro en la Revista "Polémica Procesal", año II No. 3 Medellín, Colombia, 2005.

${ }^{* *}$ Magistrado Sala Jurisdiccional Disciplinaria. Consejo Superior de la Judicatura.

${ }^{1 .}$ Corte Constitucional, expediente D-5428 Magistrado Ponente: Jaime Córdoba Triviño. 8 de junio de 2005 Sentencia C-590.
} 


\section{COLOMBIA NO CUENTA CON CORTE SUPREMA DE IUSTICIA}

Para ir aprehendiendo el tema de estudio, debemos hacer un somero recuento de lo que es el Sistema Judicial Colombiano, repaso Que sin lugar a dudas nos llevará a la unívoca conclusión Que este esquema no cuenta con una CORTE SUPREMA DE IUSTICIA. Veamos el por Qué de esta afirmación:

En la cúpula de nuestro Poder Judicial encontramos cuatro Cortes: la Corte Constitucional, la Corte Suprema de Justicia, el Consejo de Estado y el Consejo Superior de la Judicatura. La Constitución Política, delimita claramente las competencias de cada una de estas Altas Corporaciones, y ello lo podemos ver muy claro en los artículos 235, 237, 24 I, 256 y 257 de la referida normatividad superior. Es claro que nuestra Carta delimita las atribuciones de cada una de ellas, entregándoles una competencia exclusiva y excluyente, pero también debemos observar cuidadosamente que sólo tres de las Altas Cortes son operadores jurídicos Que interpretan la ley y una cuarta Corte de novísima aparición en el Sistema Colombiano, la Constitución Política.

Lo Que en otras palabras, sería de la siguiente manera: la Corte Suprema de Justicia es el órgano límite de la Jurisdicción Ordinaria (artículo 234 de la Constitución Política), con competencia exclusiva y excluyente en esta jurisdicción, y como tal entre sus atribuciones tiene la de actuar como Tribunal máximo de Casación y como consecuencia de ello, ser el unificador de la jurisprudencia nacional en la jurisdicción ordinaria (penal, laboral, civil, comercial, de familia); el Consejo de Estado es también máximo tribunal de la Jurisdicción Contencioso Administrativa, y como tal entre sus muchas funciones o competencias, está la de unificar la jurisprudencia nacional en todo lo Que atañe o tiene Que ver con la Jurisdicción
Contencioso Administrativa (artículos 237 y 238 C.P.); y la Sala Jurisdiccional Disciplinaria del Consejo Superior de la Judicatura, entre las funciones que le da la Carta Política, tiene también la de unificar la jurisprudencia disciplinaria de los funcionarios judiciales y los profesionales del Derecho.

Como vemos, no es solamente la Corte Suprema de Justicia la Que está encargada de unificar la Jurisprudencia Nacional, cada una de las Cortes en su competencia especial, unifica la jurisprudencia de su especialidad y la Corte Constitucional es la intérprete, ya no de la ley, como las anteriores, sino de la Constitución Política (artículo 24l).

A partir de aquí ya nos va Quedando claro a cada uno de nosotros las diferencias entre las cuatro Cortes, pero ahondemos un poco en el concepto de Corte Suprema de Justicia. Se ha entendido Que el Tribunal Supremo de una Nación es el órgano límite donde se resuelven por mandato de la Constitución cada uno de los conflictos judiciales Que se suscitan en determinado país, esto es, que en dicho Tribunal Supremo confluyen la jurisdicción ordinaria, la contencioso administrativa, la disciplinaria y la constitucional, siendo esta última, una Sala del Tribunal Supremo, hecho éste que no ocurre en Colombia desde 1904 cuando se creó la Sala Contencioso Administrativa, ahí ya dejó de ser SUPREMA nuestra actual Corte Suprema de Justicia, y en 1964 se crea el Tribunal Disciplinario o SuperCorte, que viene a ser hoy, después de la Carta de 1991, la Sala Jurisdiccional Disciplinaria del Consejo Superior de la Judicatura.

Pero en 1991 con la Constitución de dicho año, no solamente se conserva la separación de la justicia ordinaria y la contencioso administrativa, además de la disciplinaria Que venía desde 1964, sino que se le Quita a la Corte Suprema la Sala Constitucional y se crea la Corte Constitucional. Además de esta Corte, 
nace el Consejo Superior de la Judicatura como el órgano Que administra el Poder Judicial. Como se puede observar, a simple vista, el sistema judicial colombiano no cuenta con Corte Suprema de Justicia, en tanto, las competencias que en una Corte Suprema de Justicia se encuentran agrupadas, en nuestro sistema se encuentran separadas en las ya mencionadas y reiteradas cuatro Altas Cortes.

\section{COLOMBIA ES UN ESTADO SOCIAL DE DERECHO}

Igualmente en el año 1991, se crea la Constitución Política Que hoy nos gobierna y se da una transformación del Estado de Derecho Liberal al Estado Social de Derecho, con todas las consecuencias Que dicho salto trae aparejado, y una de las más importantes, es el reconocimiento de los derechos fundamentales el cual no requiere de desarrollo legislativo alguno, al ser éstos de inmediato cumplimiento. Como consecuencia de lo anterior, los constituyentes incorporan a nuestra Carta la acción de tutela (artículo 86 C.P.), la acción de cumplimiento (artículo 87 C.P.) y las acciones populares (artículo 88 C.P.), tres importantes instituciones, todas encaminadas a fortalecer y a hacer realidad los principios fundamentales y los valores consagrados en el preámbulo de la misma.

El artículo 86. "Toda persona tendrá acción de tutela para reclamar ante los jueces, en todo momento y lugar, mediante un procedimiento preferente y sumario, por sí misma o por Quien actúe a su nombre, la protección inmediata de sus derechos constitucionales fundamentales, cuando Quiera Que éstos resulten vulnerados o amenazados por la acción o la omisión de cualquier autoridad pública.

La protección consistirá en una orden para Que aQuél respecto de Quien se solicita la tutela, actúe o se abstenga de hacerlo. El fallo, Que será de inmediato cumplimiento, podrá impugnarse ante el juez competente $y$, en todo caso, éste lo remitirá a la Corte Constitucional para su eventual revisión.

Esta acción sólo procederá cuando el afectado no disponga de otro medio de defensa judicial, salvo Que aquélla se utilice como mecanismo transitorio para evitar un perjuicio irremediable.

En ningún caso podrán transcurrir más de diez días entre la solicitud de tutelay su resolución.

La ley establecerá los casos en los que la acción de tutela procede contra particulares encargados de la prestación de un servicio público o cuya conducta afecte grave $y$ directamente el interés colectivo, o respecto de Quienes el solicitante se halle en estado de subordinación o indefensión."

De la lectura del presente artículo, se desprende Que la acción de tutela va dirigida contra cualquier AUTORIDAD PÚBLICA y no hace ninguna excepción la Carta Política en este aspecto, y las Cortes son autoridades públicas. En consecuencia, no están exceptuadas, lo reitero, por nuestra Constitución, pero como la norma superior es el propio texto de ella y la interpretación que de la misma haga la Corte Constitucional, este alto Tribunal en la revisión del Decreto 2591 de 1991 en sus artículos II, 12 y 40, determinó Que no cabía la tutela contra sentencias judiciales (Sentencia C-543 de 1992). Pero luego en la Sentencia de tutela T079 de 1993, empieza la Corte a elaborar la doctrina de las vías de hecho en las sentencias judiciales.

La misma Corte Constitucional, ha entendido como vías de hecho: "aquellas actuaciones arbitrarias que el funcionario judicial desarrolla dentro de la dirección y sustanciación de un proceso. Por consiguiente, suceden estas circunstancias cuando el juez se aparta de la ley, 
con lo cual vulnera derechos constitucionales fundamentales."

Y siguiendo al Tribunal Constitucional, una actuación judicial se constituye en vía de hecho cuando se está en alguna de las siguientes hipótesis:

“...( I) presente un grave defecto sustantivo, es decir, cuando se encuentre basada en una norma claramente inaplicable al caso concreto; (2) presente un flagrante defecto fáctico, esto es, cuando resulta evidente que el apoyo probatorio en que se basó el juez para aplicar una determinada norma es absolutamente inadecuado; (3) presente un defecto orgánico protuberante, el cual se produce cuando el fallador carece por completo de competencia para resolver el asunto de Que se trate; y (4) presente un evidente defecto procedimental, es decir, cuando el juez se desvía por completo del procedimiento fijado por la ley para dar trámite a determinadas cuestiones." (Corte Constitucional Sentencia T-567/98. M.P. Eduardo Cifuentes Muñoz).

Y continuando la Corte Constitucional por el camino de las vías de hecho, reiteró:

"...aunque en Sentencia C-543 del I de octubre de 1992, al declarar inexequibles los artículos 11, 12 y 40 del Decreto 2591 de 1991, definió Que en principio no cabe acción de tutela contra providencias judiciales, previó en ese mismo fallo la circunstancia en la cual, por desviación en la actividad del juez, le sean imputables actuaciones de hecho Que agravien, menoscaben o amenacen derechos fundamentales de Quienes participan en el proceso o puedan ser afectados por los resultados del mismo.

En tales eventos, Que son excepcionales, la jurisprudencia ha admitido eue no existiendo medios judiciales idóneos y oportunos para restaurar los derechos vulnerados o para resguardarlos frente al acto u omisión Que los amenaza, cabe la acción de tutela, fundada en la existencia de una vía de hecho Que desvirtúa la intangibilidad del trámite judicial y despoja a la providencia de su normal respetabilidad.

La vía de hecho, tal como la ha descrito la doctrina de la Corte, corresponde a una determinación arbitraria adoptada por el juez o una omisión del mismo carácter, en virtud de la cual se atropella el debido proceso, se desconocen garantías constitucionales o se lesionan derechos básicos de las personas, en razón de una flagrante desobediencia a lo prescrito por la Constitución y la ley.

Desde luego, también se ha destacado que únicamente se configura la vía de hecho cuando pueda establecerse sin género de dudas una transgresión evidente y grave del ordenamiento jurídico, de tal entidad Que rompa por completo el esquema de equilibrio procesal instaurado en las normas aplicables.

Por supuesto, las garantías Que integran el debido proceso (art. 29 C.P.) deben preservarse íntegramente, de lo cual se infiere que la falta de cualouiera de ellas repercute en la pérdida de validez de lo actuado, y puede constituir -depende de su gravedad- una vía de hecho susceptible de la acción de tutela." (Corte Constitucional. SU 960/99 Exp. 220687 M.P. JOSE GREGORIO HERNÁNDEZ GALINDO)

Como se observa, la Corte Constitucional Quien inicialmente no aceptó la COMPETENCIA y el PODER Que le entregaba el Gobierno del Doctor CESAR GAVIRIA por medio del Decreto 2591 de 1991, y afirmaba Que en nuestro sistema Iudicial NO CABIA tutela contra las sentencias judiciales, al declarar inexequible los artículos correspondientes de dicha normatividad, desde el año de 1993 a la fecha ha venido consolidando una

\footnotetext{
Sentencia SU.542/99, Expediente T-151643. Mag. Ponente: Dr. Alejandro Martínez Caballero
} 
jurisprudencia reiterada y pacífica sobre la procedencia de la acción de tutela contra sentencias judiciales, toda enmarcada en la teoría de la VIA DE HECHO, como se expresó en precedencia.

\section{LA SALA JURISDICCIONAL DISCIPLINARIA Y LA TUTELA CONTRA SENTENCIAS DE LAS ALTAS CORTES}

De las Altas Corporaciones ya referidas, únicamente la Sala Jurisdiccional Disciplinaria del Consejo Superior de la Judicatura, ha aceptado y acatado la procedencia de la tutela contra sentencias de las Cortes límites, en sus respectivas especialidades, por cuanto el Consejo de Estado y la Corte Suprema de Justicia han rechazado esa posibilidad cuando la tutela toca alguna de sus providencias.

Pero volviendo a la Sala Jurisdiccional Disciplinaria, de la cual me honro de ser parte, siempre hemos aceptado a la Corte Constitucional como el Tribunal límite en cuanto a la acción constitucional de tutela, y como ella es la intérprete de nuestra Constitución y al interpretar la norma superior consecuentemente es la Corte de Cortes, en el sistema judicial Colombiano. Si sostenemos Que Colombia es un Estado Social de Derecho (Artículo 1 Constitución Política) tendremos Que aceptar también la afirmación anterior, referida a la supremacía de la Corte Constitucional. Lo Que en otras palabras significa Que en el poder judicial colombiano, existen cuatro cortes límite, tres de ellas interpretan la ley y la cuarta, interpreta la Constitución. Aquella que interpreta la norma Superior, obviamente es la Corte Superior y las tres Cortes que interpretan la ley, no pueden argumentar la competencia exclusiva $y$ excluyente Que les da la Carta, para negar la superioridad de la Corte Constitucional. Porque como ya se explicó, la Constitución da esas competencias exclusivas y excluyentes a las cuatro Cortes y el análisis es diferente cuando la
Corte Suprema de Justicia, el Consejo de Estado y la Sala Jurisdiccional Disciplinaria asumen el conocimiento de un determinado caso de su especialidad, Que cuando excepcionalmente actúan como jueces constitucionales. AQuí lo Que el juez tiene Que valorar es si el respectivo operador jurídico tensionó innecesariamente un derecho fundamental al conocer y fallar un asunto de su exclusiva competencia. El análisis del juez constitucional está centrado a interpretar la Constitución Política, y en el caso de la especialidad, es interpretar las leyes Que rigen la competencia correspondiente.

\section{LA CORTE SUPREMA DE JUSTICIA Y LA TUTELA CONTRA SENTENCIAS JUDICIALES}

No vemos como puede cambiar la argumentación para la Corte Suprema de Justicia y el Consejo de Estado de Que es procedente la tutela contra sentencias, cuando el operador jurídico es un juez unipersonal o un juez plural, por cuanto tal sustentación por parte de estas dos altas y respetables corporaciones se reduce a que la Constitución expresamente no se refirió a la tutela contra sentencias, lo cual es cierto, no se refirió expresamente a la acción de amparo contra providencias judiciales, pero de ningún juez por humilde que éste fuese o por encumbrado que fuese el magistrado respectivo. Pero tampoco excepcionó, como ya se dijo, la acción de tutela contra ninguna autoridad y los jueces de la República son autoridades públicas, sean estos municipales o magistrados del Consejo de Estado o Corte Suprema de Justicia. Y como no las excluyó, estas dos últimas altas corporaciones, aceptan la tutela contra sentencias judiciales de los jueces de menor rango a ellos, por vía de hecho en Que pudieran incurrir las sentencias judiciales de dichos servidores públicos. Cómo pueden resolver ellos, tamaña contradicción? La respuesta es obvia y el argumento también, porQue son órganos límites y su competencia es exclusiva y 
excluyente. Y yo agregaría: porque se creen infalibles y como tales no sujetos de equivocación ni de incurrir en vía de hecho en sus providencias contra los humildes mortales.

La Corte Suprema de Justicia en su estéril lucha de no aceptar la tutela contra sus sentencias judiciales, sólo se está Quedando con un ARGUMENTO DE AUTORIDAD en un tema tan importante Que atañe con nuestro mundo jurídico; en consecuencia, tal postulado en un asunto específico como el Que nos ocupa, se le rebate con fundamentos jurídicos. Veamos lo Que norma el artículo $5^{\circ}$ de la Ley 270 de 1996 (Ley Estatutaria de la Administración de Justicia):

"Autonomía e independencia de la Rama Judicial. La Rama Judicial es independiente y autónoma en el ejercicio de su función constitucional y legal de administrar justicia.

Ningún superior jerárquico en el orden administrativo o jurisdiccional podrá insinuar, exigir, determinar o aconsejar a un funcionario judicial para imponerle las decisiones o criterios que deba adoptar en sus providencias. " El cual sólo es el desarrollo de una norma superior como lo es el artículo 228 de la Constitución Política: "La administración de Justicia es función pública. Sus decisiones son independientes. Las actuaciones serán públicas y permanentes con las excepciones que establezca la ley y en ellas prevalecerá el derecho sustancial. Los términos procesales se observarán con diligencia y su incumplimiento será sancionado. Su funcionamiento será desconcentrado y autónomo."

Del estudio de estas dos normas, entre las muchas conclusiones Que se pueden extraer del mismo, nos Queda claro Que en el sistema judicial colombiano no se presentan jueces de superior e inferior jerarquía, sino Que existen jueces con competencias distintas o como diría el jurista IAIME ARAÚJO RENTERÍA:
El argumento de la jerareuía.

¿Qué juez de inferior jerareuía osa romper una sentencia de la Corte Suprema?.

En la rama judicial no hay jueces de superior o inferior jerarouía, no hay relación de jerarouía, lo Que existe es diversidad de competencias. Lo Que caracteriza a la rama judicial es precisamente que no puede haber órdenes o instrucciones de un juez sobre otro; es la independencia de los jueces. En la rama judicial no hay jerarQuías lo Que existe son competencias diversas. ${ }^{3 .}$

Los colombianos en general y en especial la academia, los juristas y la judicatura no se deben extrañar de las divergencias Que se suscitan entre las Altas Cortes con motivo de la procedencia de la acción de tutela contra las sentencias judiciales. Estas mismas diferencias siempre se han presentado, se presentan y se presentarán en los países Que cuentan con Tribunal Constitucional, y hoy por hoy se vive en Europa tanto en España, Italia y Alemania, donde se conoce como la GUERRA DE CORTES. En España, por ejemplo, el Tribunal Constitucional no pertenece al Sistema judicial, como sí ocurre entre nosotros. En dicho país todos los poderes públicos están sometidos al poder judicial y este a su vez se somete al Tribunal Constitucional. Rafael de Mendizábal, jurista, exMagistrado del Tribunal Supremo Español y del Tribunal Constitucional, al ser interrogado sobre la solución a las tensiones entre el Tribunal Supremo Español y la Corte Constitucional Española, afirmó: "Mi opinión es tajante: en primer lugar, hay Que consolidar la constitución y la democracia y luego perfeccionarla. Después de tener un sistema jurídico bien estructurado, habrá Que suprimir uno de los dos tribunales. De esta forma, se crearía un solo Tribunal Supremo, Que refundiría las funciones del Constitucional y del Supremo. Esa es una solución definitiva, pero no corre prisa. Las actuales tensiones, si se 
aceptan civilizadamente, no son malas, incluso son positivas. ${ }^{4 "}$

Si ustedes me preguntaran por la opinión del jurista español Que acabo de citar, yo les respondería Que estoy completamente de acuerdo con una solución radical y tajante en nuestro sistema judicial colombiano, y obviamente, la Corte Que tendría Que desaparecer sería la Corte Suprema de Justicia, por las siguientes razones:

1. El recurso extraordinario de casación es un recurso demasiado formalista,

2. Va dirigido a modificar una Sentencia de segunda instancia y por excepción una de primera instancia -casación per saltum-,

3. Se casa o modifica solamente un $2 \%$ de los recursos instaurados ante la Corte Suprema de Justicia,

4. Si observamos las causales por las cuales procede el recurso extraordinario de casación, en última instancia son las mismas causales por las Que procede la acción de tutela contra una sentencia judicial,

5. Las divergencias entre la Corte Suprema de Justicia, la Corte Constitucional y la Sala Jurisdiccional Disciplinaria, no se han llevado de una forma civilizada o enripuecedora, contrario sensu, ha sido una confrontación deslegitimadora del sistema judicial colombiano desde mi punto de vista.

6. La tutela por el contrario, legitimó a la justicia y en un país como Colombia con un conflicto de más de 40 años y actores ilegales de lado y lado, de derecha y de izeuierda, con las organizaciones delincuenciales mejor armadas y financiadas del mundo, el ciudadano común y corriente volvió a creer en el sistema judicial colombianoy esto sólo, bien vale una Corte.

La Sala Jurisdiccional Disciplinaria del Consejo
Superior de la Judicatura sin Querer, ha Quedado en la mitad del enfrentamiento entre la Corte Constitucional y la Corte Suprema de Justicia, y digo yo Que sin Querer por una sencilla razón: SI LA CORTE SUPREMA DE IUSTICIA CUMPLIERA CON LA CONSTITUCIÓN Y LA LEY, COMO ES SU DEBER Y OBLIGACIÓN, NO TENDRÍAMOS QUE ESTAR CONOCIENDO DE TUTELAS CONTRA SENTENCIAS DE TAN ALTA CORPORACIÓN.

La Corte Suprema de Justicia no Quiere cumplir con la Constitución ni con la ley

El Gobierno del doctor ANDRÉS PASTRANA ARANGO, en un intento de terminar o hacer más llevadero el conflicto entre las diferentes Cortes, dictó el Decreto 1382 del año 2000, respecto del cual la Corte Suprema de Justicia afirma Que está de acuerdo a la ley y la Constitución; Que como consecuencia de él, no tiene competencia la Sala Jurisdiccional Disciplinaria para conocer de acciones de tutela Que vayan dirigidas contra sentencias de alguna de sus tres salas de casación. En lo que estamos totalmente de acuerdo con la Honorable Corte Suprema de Justicia, y por este medio le pediríamos eue dejara la rebeldía a aceptar el sistema judicial colombiano, Que rige a nuestro país desde el 4 de julio de 1991, y a su vez, cumpliera también con el Decreto 1382 del año 2000 y conociera tal como lo ordena dicha norma, de las acciones de tutela Que van dirigidas contra alguna de sus salas de casación, y una vez aprehendiera el negocio respectivo, y se cumpliera con los trámites de acuerdo al Decreto 2591 de 1991 en concordancia con el 306 de 1992, enviara para su eventual revisión dichas acciones de tutela a la Corte Constitucional conforme con lo normado en el artículo 24I numeral 9 de nuestra Carta Política.

3. ARAÚJO RENTERÍA, JAIME. Procedencia de la acción de tutela contra providencias judiciales. Conferencia dictada en la Universidad Externado de Colombia. Tercer Encuentro de la Jurisdicción Constitucional.

4. ÁMBITO JURÍDICO. Año VIII. No. 176 Bogotá, 9 al 22 de mayo de 2005. "Las tensiones entre las Altas Cortes son el producto de la adaptación de las normas" Sección B pág. 3 B 
Nuestra Sala Jurisdiccional Disciplinaria de manera mayoritaria acepta la constitucionalidad y legalidad del Decreto 1382 del año 2000 y para avocar el conocimiento de una acción de tutela Que va dirigida contra una de las Salas de Casación de la Corte Suprema de Justicia exige como requisito de procedibilidad el Que dicha acción haya sido interpuesta primeramente ante la Corte Suprema de Justicia, tal y como lo norma el tan reiterado Decreto 1382 del 2000 y Que esta alta corporación se haya negado a conocer de la misma. (Abierta rebeldía de la Corte Suprema de Justicia al sistema judicial colombiano, por desconocimiento descarado de la Constitución Política).

El fundamento jurídico para actuar de esta manera por parte de la Sala mayoritaria de la cual yo hago parte, lo constituyen los autos expedidos por la Sala Plena de la Corte Constitucional los días 3 y 17 de febrero de 2004, mediante los cuales decidió sobre un buen número de tutelas instauradas ante la Corte Suprema de Justicia y frente a las cuales esta Corporación resolvió no admitir su trámite, expresándose allí:

"Primero.- Decidir que los accionantes a los que se refiere la parte motiva de esta providencia, de conformidad con lo establecido en el artículo $37 \mathrm{del}$ decreto 2591 de 1991 tienen el derecho de acudir ante cualquier juez (unipersonal o colegiado), incluyendo una Corporación de igual jerarquía a la Corte Suprema de Justicia, para reclamar mediante la acción de tutela la protección del derecho fundamental que consideran violado con la actuación de una Sala de Casación de dicha Corte. Por secretaría ofíciese a cada uno de los accionantes.

Segundo. - Para otros casos en que exista la misma situación de vulneración del derecho de acceso a la administración de justicia y la no tutela judicial efectiva de sus derechos fundamentales, por no admitir a trámite la acción de tutela contra providencia de la Corte Suprema de Justicia, con fundamento en el artículo 37 del decreto 2591 de 1991 los ciudadanos tienen el derecho de acudir

\begin{abstract}
ante cualquier juez (unipersonal o colegiado), incluyendo una Corporación de igual jerarquía a la Corte Suprema de justicia, para reclamar mediante una acción de tutela la protección del derecho fundamental que consideran violado con la actuación de una Sala de Casación de dicha Corte".
\end{abstract}

Además de los autos de la Corte Constitucional, la Sala Jurisdiccional Disciplinaria se fundamenta en el artículo 86 de la Constitución Política y en el artículo 229 de la misma Carta, Que garantiza el acceso pleno a la administración de justicia a toda persona, y los fines esenciales del Estado consagrados en el artículo $2^{\circ}$ de este mismo estatuto.

Desde el 21 de abril del año 2004, la Sala Jurisdiccional Disciplinaria ha venido tutelando semanalmente entre 5 a 10 sentencias contra la Sala de Casación Laboral de la Corte Suprema de Justicia, por negarse esta última corporación a reconocer la indexación de la primera mesada pensional, desconociendo la sentencia SU- 120 de 2003 de la Corte Constitucional.

Como consecuencia de lo anterior, dicha Corporación ha decidido denunciar por prevaricato a los Magistrados de nuestras Seccionales que en cumplimiento de autos emanados de la Sala Jurisdiccional Disciplinaria avocan el conocimiento de acciones de tutela contra la Corte Suprema de Justicia, en un intento desesperado por amedrentar a nuestros operadores jurídicos. Parece ser Que la vanidad de los integrantes de la Corte Suprema de Justicia les haga desconocer los elementos integradores del tipo penal de prevaricato por acción en nuestro sistema penal colombiano, y prefieren pasar por ignorantes ante el país que acatar la Constitución y la ley.

Afortunadamente, los Fiscales ante la Corte Suprema de Justicia, no se han dejado halagar por esta Corporación y han actuado en estricto derecho, cuando de resolver la situación jurídica de nuestros magistrados se trata. Y digo que no se han dejado halagar, poreue para 
nadie es un secreto que la Corte Suprema de Justicia, elige a sus Magistrados de listas Que le envía la Sala Administrativa del Consejo Superior de la Judicatura y es lógico Que un fiscal ante la Corte Suprema de Justicia, tenga entre sus aspiraciones ser miembro de esta alta Corporación. Ahí radica el peligro de Que un Fiscal pueda caer en la tentación de no actuar en estricto derecho y empieza a flaquear el sistema judicial colombiano Que por temor los operadores jurídicos -entiéndase Magistrados de Seccionales- no cumplan también con su deber y en este caso sólo hay un perjudicado: la justicia, y como consecuencia de ello, se deslegitime el Poder Judicial, con los resultados funestos Que trae aparejado para el Estado Social de Derecho. Todo a cambio de la vanidad de una Corte que se cree infalible, y por ende sus providencias intangibles, inmutables e inmodificables.

Pero no deja de ser preocupante Que una Corte límite le esté dando por denunciar magistrados de Tribunales por el sólo prurito de haber tutelado alguna de sus sentencias por haber incurrido esta alta corporación en una vía de hecho. No es sano para la justicia colombiana Que una alta Corte trate de amedrentar por todos los medios a los operadores jurídicos y se le está volviendo tarde al país de reaccionar por esta conducta de tan alto tribunal.

Olvídense pues los Magistrados de la Corte Suprema de Justicia que nos van a amilanar, y por el contrario, cuenta Colombia con una Corporación que administra justicia autónoma e independientemente, Que no acepta presiones de ninguna autoridad pública y mucho menos de una Corporación que está en el mismo límite del poder judicial Que nosotros, pero esto no Quiere decir Que no nos preocupe la conducta de una Corte que está en abierta rebeldía con el sistema judicial colombiano y Que primero trató de deslegitimar a la Sala Jurisdiccional Disciplinaria con el torpe argumento de su origen, en tanto orgullosamente, somos elegidos por el Congreso Colombiano y por ello estamos más cerca del constituyente primario y es mucho más legítima nuestra elección due la de los Magistrados de la Corte Suprema de Justicia.

Y cuando el argumento de nuestro origen no le dio resultado, trata de recurrir al absurdo de denunciar a los magistrados que cumplimos con nuestra Constitución y la ley, por un presunto prevaricato por acción.

Que esta lucha incivilizada de la Corte Suprema, por no aceptar la Constitución, no nos lleve a recurrir a las Cortes internacionales.

\section{BIBLIOGRAFÍA}

ÁMBITO JURÍDICO No. 176 del 9 al 22 de mayo de 2005 Sección B página 3 B

ARAúJO RENTERÍA JAIME, Procedencia de la Acción de tutela contra providencias judiciales, Conferencia dictada en la Universidad Externado de Colombia. Tercer Encuentro de la Jurisdicción Constitucional.

BERNAL PULIDO CARLOS, El Derecho de los derechos, Editorial Universidad Externado de Colombia, primera reimpresión

\section{CONSTITUCIÓN POLÍTICA}

CORTE CONSTITUCIONAL Sentencias C543 de 1992, T-079 de 1993; T-567 de 1998; SU 960 de 1999; SU 120 de 2003

DECRETOS 2591 de 1991; 306 de 1992; 1382 de 2000

Ley Estatutaria de la Administración de Justicia (270 de 1996) 